\title{
Glycemic control with empagliflozin, a novel selective SGLT2 inhibitor, ameliorates cardiovascular injury and cognitive dysfunction in obese and type 2 diabetic mice
}

Bowen Lin, Nobutaka Koibuchi, Yu Hasegawa, Daisuke Sueta, Kensuke Toyama, Ken Uekawa, MingJie Ma, Takashi Nakagawa, Hiroaki Kusaka and Shokei Kim-Mitsuyama*

\begin{abstract}
Background: There has been uncertainty regarding the benefit of glycemic control with antidiabetic agents in prevention of diabetic macrovascular disease. Further development of novel antidiabetic agents is essential for overcoming the burden of diabetic macrovascular disease. The renal sodium glucose co-transporter 2 (SGLT2) inhibitor is a novel antihyperglycemic agent for treatment of type 2 diabetes. This work was performed to determine whether empagliflozin, a novel SGLT2 inhibitor, can ameliorate cardiovascular injury and cognitive decline in $\mathrm{db} / \mathrm{db}$ mouse, a model of obesity and type 2 diabetes.
\end{abstract}

Methods: (1) Short-term experiment: The first experiment was performed to examine the effect of 7 days of empagliflozin treatment on urinary glucose excretion and urinary electrolyte excretion in $\mathrm{db} / \mathrm{db}$ mice. (2) Long-term experiment: The second experiment was undertaken to examine the effect of 10 weeks of empagliflozin treatment on cardiovascular injury, vascular dysfunction, cognitive decline, and renal injury in $\mathrm{db} / \mathrm{db}$ mice.

Results: (1) Short-term experiment: Empagliflozin administration significantly increased urinary glucose excretion, urine volume, and urinary sodium excretion in $\mathrm{db} / \mathrm{db}$ mice on day 1 , but did not increase these parameters from day 2. However, blood glucose levels in $\mathrm{db} / \mathrm{db}$ mice were continuously decreased by empagliflozin throughout 7 days of the treatment. (2) Long-term experiment: Empagliflozin treatment caused sustained decrease in blood glucose in $\mathrm{db} / \mathrm{db}$ mice throughout 10 weeks of the treatment and significantly slowed the progression of type 2 diabetes. Empagliflozin significantly ameliorated cardiac interstitial fibrosis, pericoronary arterial fibrosis, coronary arterial thickening, cardiac macrophage infiltration, and the impairment of vascular dilating function in $\mathrm{db} / \mathrm{db}$ mice, and these beneficial effects of empagliflozin were associated with attenuation of oxidative stress in cardiovascular tissue of $\mathrm{db} / \mathrm{db}$ mice. Furthermore, empagliflozin significantly prevented the impairment of cognitive function in $\mathrm{db} / \mathrm{db}$ mice, which was associated with the attenuation of cerebral oxidative stress and the increase in cerebral brain-derived neurotrophic factor. Empagliflozin ameliorated albuminuria, and glomerular injury in db/db mice.

Conclusions: Glycemic control with empagliflozin significantly ameliorated cardiovascular injury and remodeling, vascular dysfunction, and cognitive decline in obese and type 2 diabetic mice. Thus, empagliflozin seems to be potentially a promising therapeutic agent for diabetic macrovascular disease and cognitive decline.

Keywords: Cardiovascular complications, Vascular dysfunction, Cognitive decline, Oxidative stress, Inflammation

\footnotetext{
* Correspondence: mitsuyam@gpo.kumamoto-u.ac.jp

Department of Pharmacology and Molecular Therapeutics, Kumamoto

University Graduate School of Medical Sciences, 1-1-1 Honjyo, Kumamoto 860-8556, Japan
}

\section{Biomed Central}

(c) 2014 Lin et al.; licensee BioMed Central Ltd. This is an Open Access article distributed under the terms of the Creative Commons Attribution License (http://creativecommons.org/licenses/by/4.0), which permits unrestricted use, distribution, and reproduction in any medium, provided the original work is properly credited. The Creative Commons Public Domain Dedication waiver (http://creativecommons.org/publicdomain/zero/1.0/) applies to the data made available in this article, unless otherwise stated. 


\section{Background}

Type 2 diabetes is a major risk factor for cardiovascular disease and cardiovascular disease is the leading cause of mortality in patients with diabetes $[1,2]$. Previous large clinical trials have established that strict glycemic control significantly reduces diabetic microvascular complications such as nephropathy or retinopathy [3-5]. On the other hand, to date there has been uncertainty regarding whether any current antihyperglycemic agents can actually reduce cardiovascular event, because most of previous clinical trials indicated no benefit of current antihyperglycemic agents in prevention of cardiovascular disease [3-8]. Moreover, diabetes is a major risk factor for cognitive decline as well as cardiovascular disease [9-11]. However, no information is available regarding the effect of antihyperglycemic agents on cognitive decline in diabetes. Hence, further development of other novel pharmacological approaches of glycemic control is necessary to reduce macrovascular disease and cognitive impairment in patients with diabetes.

The kidney plays a key role in glucose homeostasis and has recently become a target organ for treatment of diabetes. Under normal conditions, the kidney reabsorbs all the glucose from the glomerular filtrate and back into the blood. Sodium glucose co-transporter 2 (SGLT2) is located in the brush border membrane of the proximal convoluted tubule of the nephron, and mediates the majority of glucose reabsorption from glomerular filtrate $[12,13]$. Pharmacological inhibition of SGLT2 increases urinary glucose excretion (UGE) and consequently decreases blood glucose levels in an insulin-independent manner [12,13]. Thus, SGLT2 inhibitors represent a novel class of antihyperglycemic drugs and have recently become available for treatment of patients with type 2 diabetes [12-15]. It is a future clinical key issue whether SGLT2 inhibitor can prevent macrovascular complication, cognitive decline, or microvascular complication in diabetic patients. Previous preclinical studies using diabetic animal models support the notion that SGLT2 inhibitors may exert protective effects against diabetic nephropathy (diabetic microvascular disease) [16-21]. However, to the best of our knowledge, the effect of SGLT2 inhibition on cardiovascular disease and cognitive function in diabetes remains to be explored.

Empagliflozin [22-24] is a novel inhibitor of SGLT2, and is characterized by highly selective and potent inhibitor of SGLT2, compared with other SGLT2 inhibitors. In the present experimental study, we hypothesized that glycemic control with empagliflozin can ameliorate cardiovascular injury and cognitive decline in obese and type 2 diabetic mice. To demonstrate our hypothesis, we examined the effects of long-term empagliflozin treatment on cardiac fibrosis and inflammation, coronary arterial remodeling, vascular dysfunction, cardiovascular oxidative stress, and learning and reference/working memory in $\mathrm{db} / \mathrm{db}$ mice, a useful model of obesity and type 2 diabetes. We obtained the evidence that empagliflozin may be a promising therapeutic agent for diabetic macrovascular disease and cognitive decline.

\section{Methods}

\section{Animals}

All procedures were performed in accordance with institutional guidelines for animal research and were approved by the Animal Care and Use Committee of Kumamoto University. Male db/db mice (C57BLKS/J-lepr ${ }^{\mathrm{db}} /$ lepr $^{\mathrm{db}}$ ) and male nondiabetic and lean $\mathrm{db} / \mathrm{m}$ mice (C57BLKS/Jlepr $\mathrm{db}^{\mathrm{db}} /+$ ) as control were purchased from Japan Charles River Laboratories Japan Inc. (Yokohama, Japan). All animals were housed in an animal facility with a 12-hour light-dark cycle and were given the standard chow and water ad libitum.

\section{Drugs}

Empagliflozin [22-24], a selective sodium glucose cotransporter-2 (SGLT2) inhibitor, was kindly gifted from Boehringer Ingelheim Pharma GmbH \& Co.KG, Germany.

\section{Experiment I: Effect of short-term (7 days) empagliflozin administration}

The main objective of Experiment I was to investigate the effect of short-term (7 days) empagliflozin treatment on urinary glucose excretion, urine volume, urinary electrolytes, and blood glucose. $\mathrm{db} / \mathrm{db}$ mice at 7 weeks of age already displayed significant obesity and type 2 diabetes. Therefore, in this study, drug treatment of $\mathrm{db} / \mathrm{db}$ mice was initiated from 7 weeks of age. $d b / d b$ mice were acclimatized to the metabolic cages to collect 24-hour urine samples every day from 5 days before the experiment, randomly assigned 2 groups, and were given (1) the standard diet (MF diet, ORIENTAL YEAST Co., Ltd, Tokyo, Japan) (2) the standard diet containing $0.03 \%$ empagliflozin for 7 days and 24-hour urine samples were collected from each mouse every day. Non fasting blood glucose was measured before and 1, 3, and 7 days after start of empagliflozin administration.

Furthermore, the effect of short-term empagliflozin treatment was also examined in non-diabetic $\mathrm{db} / \mathrm{m}$ mice in the same manner as the above mentioned experiment on $\mathrm{db} / \mathrm{db}$ mice.

Experiment II: Effect of long-term (10 weeks) empagliflozin administration on cardiovascular complications, cognitive function, and renal injury

Experiment II was performed to mainly investigate the effects of long term empagliflozin treatment on cardiovascular injury, vascular dysfunction, cognitive dysfunction, and renal injury. Seven-week-old $\mathrm{db} / \mathrm{db}$ mice were assigned 
to 2 groups, and were given (1) the standard diet (MF diet, ORIENTAL YEAST Co., Ltd, Tokyo, Japan) or (2) the standard diet containing $0.03 \%$ empagliflozin in the same manner as the Experiment $\mathrm{I}$, and drug treatment was performed for 10 weeks. The design of the Experiment II is shown in Figure 1. Body weight and blood glucose were periodically measured every week throughout the treatment. Blood samples were collected from the tail vein of mice for measurement of non-fasting blood glucose. Blood pressure (BP) was measured at 3 and 8 weeks after the start of drug treatment. After 4 and 8 weeks of drug treatment, mice were housed in metabolic cages to collect 24-hour urine for measurement of urinary glucose, urinary electrolytes, urinary albumin, and urinary creatinine excretions. Oral glucose tolerance test was performed after 7 weeks of drug treatment. Morris water maze test (MWM) was performed at 9 weeks of drug treatment. At the end of 10 weeks of treatment, 17-weekold $\mathrm{db} / \mathrm{db}$ mice were anaesthetized with isoflurane, the blood was collected by cardiac puncture, to measure serum insulin and glucose. The heart, thoracic aorta and kidney were rapidly excised to perform histological and biochemical examinations, as described below in detail.

\section{Experiment III: Effect of empagliflozin administration on cerebral oxidative stresss and brain-derived neurotrophic} factor of $\mathrm{db} / \mathrm{db}$ mice

To examine the effect of empagliflozin on cerebral oxidative stress and brain-derived neurotrophic factor (BDNF) in $\mathrm{db} / \mathrm{db}$ mice, empagliflozin treatment was performed on $\mathrm{db} / \mathrm{db}$ mice for 16 days in the same manner as the above experiment, and cerebral tissue was collected from each mouse by the modification of our previous method [25].

\section{Measurement of blood pressure}

Blood pressure was measured by tail-cuff plethysmography (BP-98A; Softron Co, Tokyo, Japan).

\section{Oral glucose tolerance test}

Mice were deprived of food for overnight and then orally given glucose ( $1 \mathrm{mg} / \mathrm{g}$ body weight). Tail vein bloods were taken from mice at $0,30,60$ and 120 min after glucose administration to measure serum glucose concentrations. Blood glucose concentrations were measured by a portable glucose meter (Sanwa Kagaku Kenkyusho CO., LTD, Nagoya, Japan).

\section{Vessel ring preparation and organ chamber experiments}

Isometric tension studies were performed, as previously described [26]. In brief, thoracic aortas from mice were cut into $5 \mathrm{~mm}$ rings, and mounted in organ baths filled with modified Tyrode buffer ( $\mathrm{pH} 7.4 ; \mathrm{NaCl} 121 \mathrm{mmol} / \mathrm{l}$, $\mathrm{KCl} 5.9 \mathrm{mmol} / \mathrm{l}, \mathrm{CaCl}_{2} 2.5 \mathrm{mmol} / \mathrm{l}, \mathrm{MgCl}_{2} 1.2 \mathrm{mmol} / \mathrm{l}$, $\mathrm{NaH}_{2} \mathrm{PO}_{4} 1.2 \mathrm{mmol} / \mathrm{l}, \mathrm{NaHCO}_{3} 15.5 \mathrm{mmol} / \mathrm{l}$, and $\mathrm{D}$ (+)-glucose $11.5 \mathrm{mmol} / \mathrm{l}$ ) aerated with $95 \% \mathrm{O}_{2}$ and $5 \%$ $\mathrm{CO}_{2}$ at $37^{\circ} \mathrm{C}$. The preparations were attached to a force transducer, and isometric tension was recorded on a polygraph. A resting tension of $1 \mathrm{~g}$ was maintained throughout the experiment. Vessel rings were precontracted with L-phenylephrine $\left(10^{-7} \mathrm{~mol} / \mathrm{l}\right)$. After the plateau was attained, the rings were exposed to increasing concentrations of acetylcholine $\left(10^{-9} \mathrm{~mol} / \mathrm{l}\right.$ to $\left.10^{-4} \mathrm{~mol} / \mathrm{l}\right)$ or Snitroso-N-acetylpenicillamine (SNAP) $\left(10^{-9} \mathrm{~mol} / \mathrm{l}\right.$ to $10^{-4}$ $\mathrm{mol} / \mathrm{l})$ to obtain cumulative concentration-response curves.

\section{Measurement of tissue superoxide}

Heart, aorta, kidney, and brain removed from mice, were immediately frozen in Tissue-Tek O.C.T. embedding medium (Sakura Finetek, Tokyo, Japan). Dihydroethidium (DHE) was used to evaluate tissue superoxide levels in situ, as described [27]. DHE fluorescence of each tissue section was quantified by Lumina Vision version 2.2 (Mitani corporation, Tokyo, Japan). The mean fluorescence was quantified and expressed relative to values obtained from control mice.

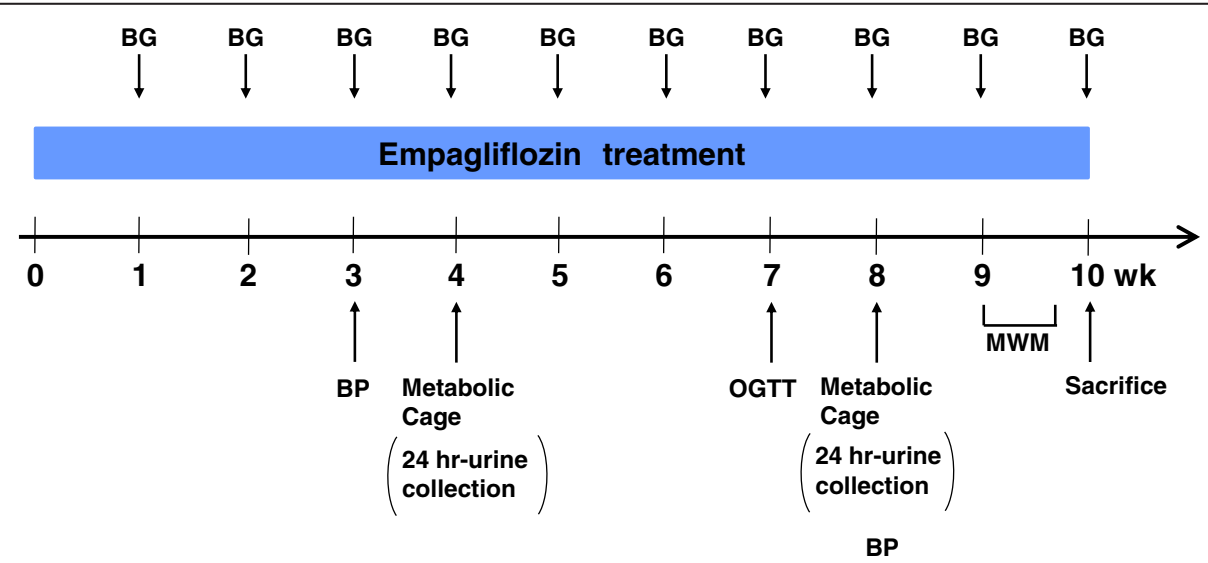

Figure 1 The design of Experiment II. Abbreviations used: BG, measurement of blood glucose; BP, measurement of blood pressure; OGTT, oral glucose tolerance test; MWM, Moris water maze test. 


\section{Measurement of cerebral 8-hydroxy-deoxyguanosine (8-OHdG)}

For measurement of cerebral 8-OHdG, cerebral DNA was extracted with DNA Extractor TIS kit (Wako Pure Chemical Industries, Ltd. Osaka, Japan) and cerebral 8-OHdG was measured by New 8-OHdG Check ELISA (Japan Institute for the Control of Aging, NIKKEN SEIL CO., Ltd. Tokyo, Japan).

\section{Histological and immunohistochemical analysis}

Hearts were fixed in $4 \%$ (wt/vol.) paraformaldehyde, embedded in paraffin, sectioned 5- $\mu \mathrm{m}$ slices, and stained with Sirius Red F3BA $(0.5 \% \mathrm{wt} / \mathrm{vol}$. in saturated aqueous picric acid; Aldrich Chemical Company, St Louis, MO, USA) for the measurement of cardiac interstitial fibrosis, pericoronary arterial fibrosis and coronary arterial thickness. The area of fibrosis and coronary arterial thickness was analyzed by Lumina Vision version 2.2 (Mitani corporation, Tokyo, Japan). Kidneys were fixed in $4 \%$ paraformaldehyde, embedded in paraffin, sectioned $5-\mu \mathrm{m}$ slices, and stained with periodic acid-Schiff (PAS). Glomerular sclerosis was assessed in PAS stained kidney sections by a semiquantitative score (grades 0 to +4 ), as previously described [28]. Fifty glomeruli were randomly selected from each mouse to perform the analysis.

For detection of cardiac and glomerular macrophage infiltration, frozen cardiac and kidney sections were incubated overnight with the primary antibody(rat anti-mouse CD68, Serotec; $\times 1000)$ followed by anti-rat secondary antibody (BioSource, Camarillo, CA, USA), as described previously [28].

\section{Morris water maze test}

Learning and reference/working memory were evaluated by the Morris water maze (MWM) test, as previously described [29]. Groups were blinded to the examiners. In brief, swimming paths were video-tracked with a camera fixed on the ceiling of the room and analyzed by the software (Muromachi Kikai, Tokyo, Japan). A training session was carried out before the hidden platform
(A)

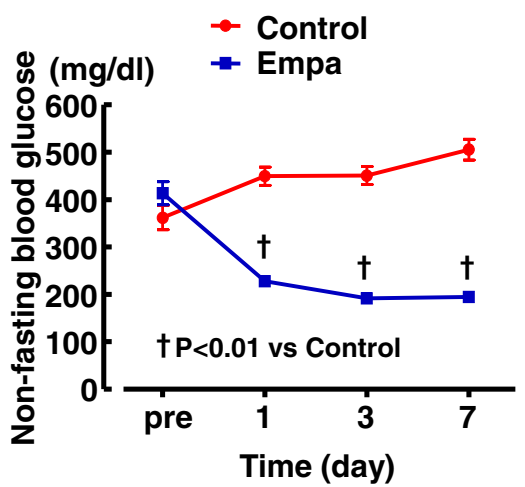

(C)

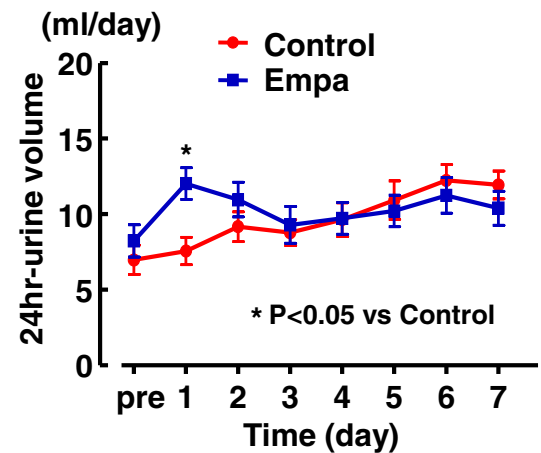

(B)

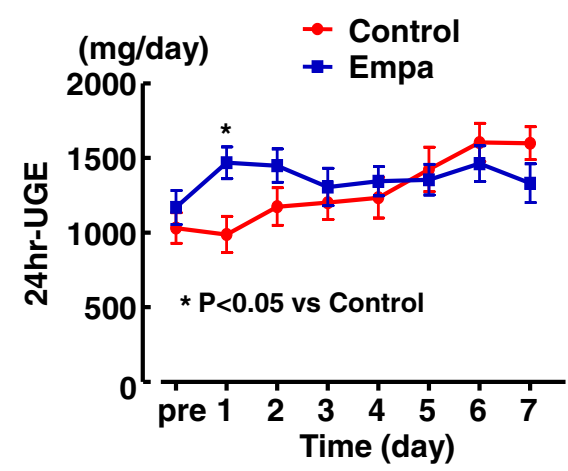

(D)

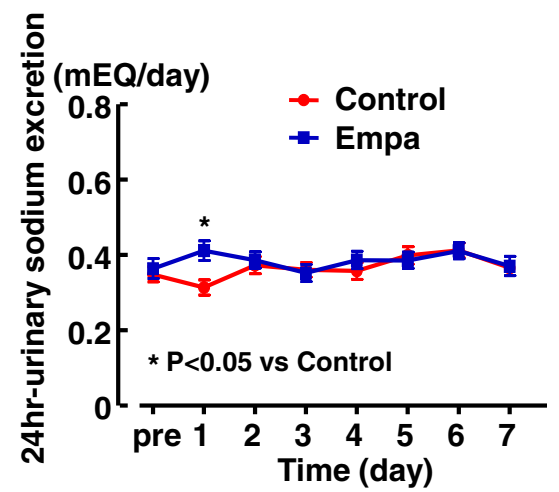

Figure 2 Effects of short-term (7 days) empagliflozin administration on non-fasting blood glucose (A), 24 hr-urinary glucose excretion (B), 24 hr-urine volume (C) and 24 hr-urinary sodium excretion (D) in $\mathbf{~ d b / d b}$ mice. Twenty four-hour urine of each mouse was collected with metabolic cages every day before and throughout the experiment. Abbreviations used: UGE, urinary glucose excretion; control, control (untreated) $\mathrm{db} / \mathrm{db}$ mice; Empa, empagliflozin-treated db/db mice; pre, the data obtained before start of drug treatment. ${ }^{*} \mathrm{p}<0.05$, $+\mathrm{p}<0.01 \mathrm{vs}$ control db/db mice. Values are mean \pm SEM $(n=10-11)$. 
test sessions. Mice were given 60 seconds free swimming and guided to climb onto the hidden platform and allowed to remain there for 30 seconds before returning to their cages. On the hidden platform test, the mice had 5 sessions at 20-minute intervals per day on the following 4 consecutive days (day 1 to 4 ). During each session mice were released from randomly assigned 3 starting points and swam for 100 seconds. On the probe test at day 5, the hidden platform was removed and the mice swam freely for 100 seconds. The number of times the mice crossed the original platform location was recorded. On the visible platform test which was performed after the probe test on day 5 , the platform was elevated $5 \mathrm{~cm}$ above the water surface level and placed in a different position. The mice were given four sessions of a visible trial with an inter-session interval of 20 minutes.

\section{Western blot analysis}

Western blot analysis of cerebral tissue protein was performed by our previous method described [30]. Antibodies used were as follows: anti-gp91phox (91kDa) (x2000, Santa Cruz Biotechnology, Inc., Santa Cruz, CA, USA), anti-p67phox (67kDa) (x5000, BD Biosciences, San Jose, CA, USA), anti-BDNF (14kDa) (x2000, Santa Cruz Biotechnology, Inc., Santa Cruz, CA, USA), anti-GAPDH (37kDa) (x5000, Santa Cruz Biotechnology, Inc., Santa Cruz, CA, USA). The intensity of the bands was quantified using NIH Image analysis software v1.61. In individual samples, each value was corrected for that of GAPDH.

\section{Analysis of biochemistry}

Serum insulin levels were quantified by using a commercial ELISA kit (Morinaga, Tokyo, Japan). Urine biochemistry were performed at SRL Inc (Tokyo, Japan).

\section{Statistical analysis}

Statistical analysis was performed using GraphPad Prism version 5.02 for Windows (GraphPad Software Inc., San Diego, CA) and Ekuseru-Tokei 2012 statistical software (Social Survey Research Information Co, Ltd, Tokyo, Japan). Data were presented as mean \pm SEM. The data on time course experiments were analyzed by two-way ANOVA

\section{(A)}

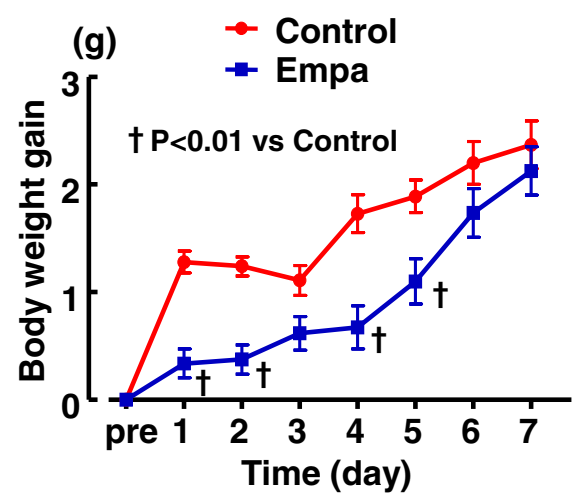

(C)

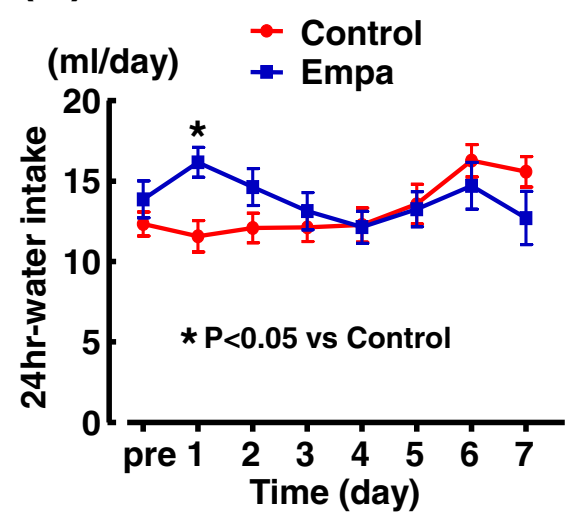

(B)

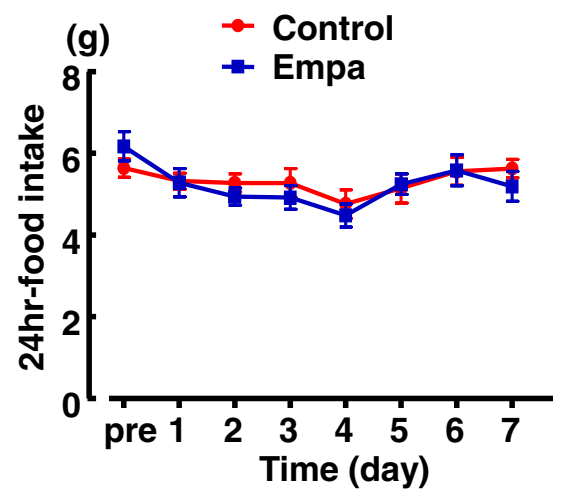


with repeated measures followed by Bonferroni post hoc test for multiple comparisons. Statistical significance was determined with one-way ANOVA, followed by the Newman-Keuls post hoc test between each group. Data were analyzed with the Kruskal-Wallis test followed by Steel-Dwass post hoc test, when similar variances were not obtained among comparison groups or a normal distribution was not confirmed among comparison groups. In all tests, differences were considered statistically significant at a value of $\mathrm{P}<0.05$.

\section{Results}

The effects of short-term (7 days) empagliflozin treatment on blood glucose, urinary parameters and body weight of $\mathrm{db} / \mathrm{db}$ mice and non-diabetic $\mathrm{db} / \mathrm{m}$ mice

Figure 2 shows the time course of non-fasting blood glucose, 24-hr urinary glucose excretion, 24-hr urine volume and 24-hr urinary sodium excretion in control and empagliflozin-treated $\mathrm{db} / \mathrm{db}$ mice. Non-fasting blood glucose of $\mathrm{db} / \mathrm{db}$ mice was already significantly reduced on day 1 after start of empagliflozin administration and remained significantly decreased throughout 7 days of the treatment (Figure 2 (A)). Only on day 1, 24-hr urinary glucose excretion, urine volume and urinary sodium excretion (in Figure 2 (B), (C), and (D), respectively) were significantly increased in $\mathrm{db} / \mathrm{db}$ mice given empagliflozin, but these parameters did not differ between empagliflozin and control groups from day 2.

As shown in Figure 3(A), body weight gain of empagliflozin group was less than that of control group on day 1-5 (except for day 3) after start of the treatment, but there was no significant difference in body weight gain between the groups on day 6 and 7. As shown in Figure 3 (B), empagliflozin treatment did not affect food intake compared with control throughout the treatment. Water intake of $\mathrm{db} / \mathrm{db}$ mice was significantly increased by empagliflozin only day 1 (Figure $3(C)$ ).

We also examined the effect of short-term empagliflozin treatment in non-diabetic $\mathrm{db} / \mathrm{m}$ mice. As shown in Figure 4, empagliflozin treatment significantly increased 24-hr urinary glucose excretion, urine volume, sodium excretion, and water intake, and significantly lessened

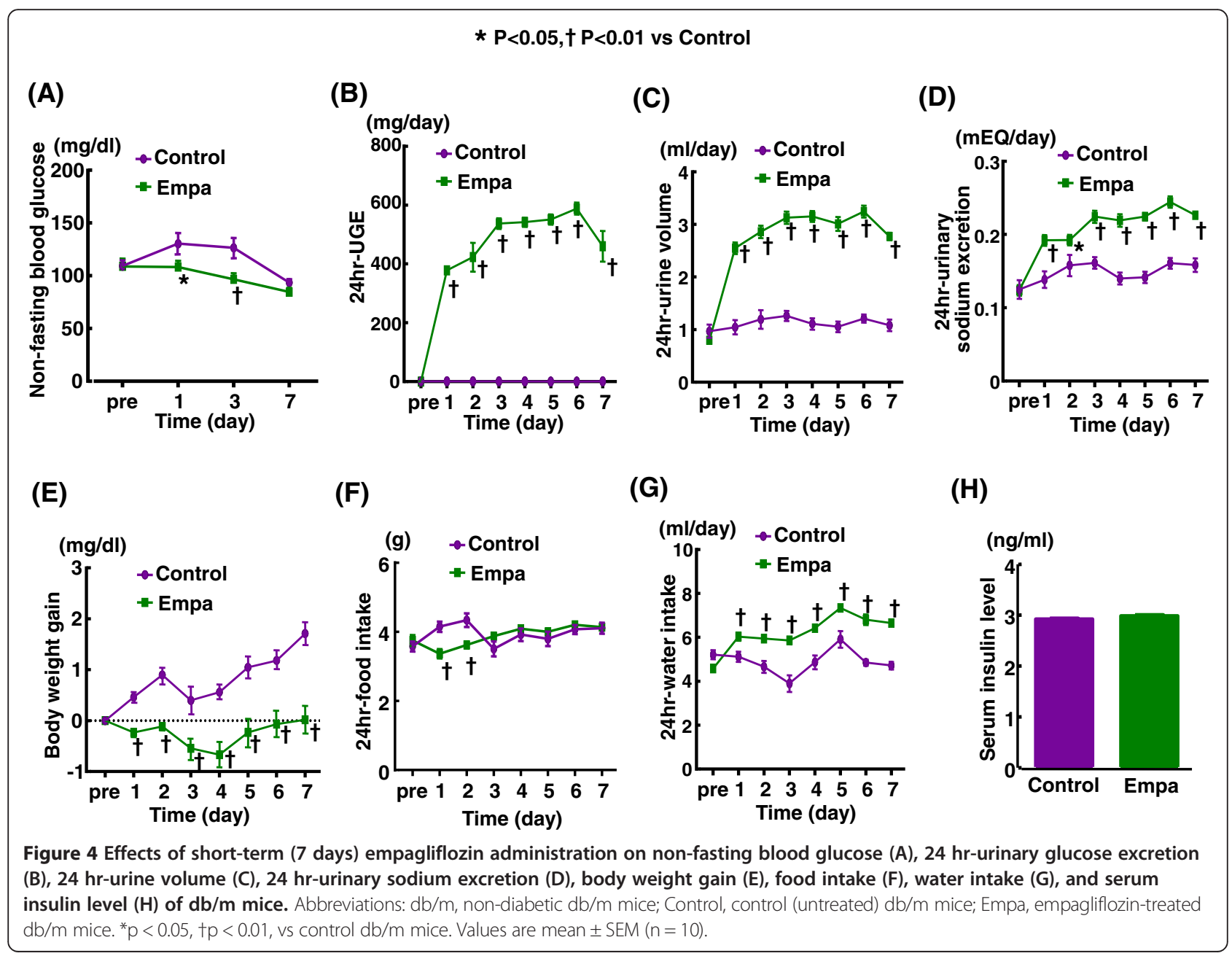


body weight gain of $\mathrm{db} / \mathrm{m}$ mice throughout the treatment. However, at the end of drug treatment (after 7 days of treatment), relative to control, empagliflozin did not significantly alter blood glucose levels $(93.5 \pm 3.2 \mathrm{mg} / \mathrm{dl}$ vs $84.7 \pm 4.0 \mathrm{mg} / \mathrm{dl})$ or serum insulin levels $(2.92 \pm 0.03$ vs $2.99 \pm 0.03(\mathrm{ng} / \mathrm{ml}))$ in $\mathrm{db} / \mathrm{m}$ mice.

The effects of long-term (10 weeks) empagliflozin treatment on hyperglycemia, serum insulin, body weight, urinary parameters, and blood pressure of $\mathrm{db} / \mathrm{db}$ mice

As shown in Figure 5(A), non-fasting blood glucose levels of $\mathrm{db} / \mathrm{db}$ mice were much less in empagliflozintreated group than in control group throughout 10 weeks of the treatment. Oral glucose tolerance test in Figure 5(B) indicates that empagliflozin improved glucose tolerance in $\mathrm{db} / \mathrm{db}$ mice to almost similar levels to nondiabetic $\mathrm{db} / \mathrm{m}$ mice. As shown in Figure $5(\mathrm{C})$, serum insulin levels were not different between $\mathrm{db} / \mathrm{m}$ mice and control (untreated) $\mathrm{db} / \mathrm{db}$ mice at the end of 10 weeks of the treatment (at the age of 17 weeks). However, serum insulin levels in empagliflozin-treated $\mathrm{db} / \mathrm{db}$ mice were higher than those in control $\mathrm{db} / \mathrm{db}$ mice $(\mathrm{p}<0.05)$ (Figure $5(\mathrm{C})$ ). Body weight of $\mathrm{db} / \mathrm{db}$ mice subjected to empagliflozin treatment was significantly larger than those of control $\mathrm{db} / \mathrm{db}$ mice after 7 weeks of the treatment (Figure 5(D)).

Figure 6(A)-(E) indicate the data obtained from 24-hour urine samples collected with metabolic cages at 4 and 8 weeks after start of empagliflozin treatment. Urinary glucose excretion and urine volume (Figure $6(\mathrm{~A})$ and (B), respectively) were significantly smaller in empagliflozin group than in control group. There was no significant difference in urinary sodium excretion (Figure $6(\mathrm{C})$ ), food intake (Figure 6 (D)) or water intake (Figure $6(\mathrm{E})$ ) between empagliflozin-treated and control $\mathrm{db} / \mathrm{db}$ mice, except for the significant decrease in water intake in empagliflozin group at 4 weeks.

Figure $6(\mathrm{~F})$ shows blood pressure at 3 and 8 weeks after start of the treatment. Blood pressure was comparable between control and empagliflozin-treated $\mathrm{db} / \mathrm{db}$ mice.

Effects of empagliflozin on cardiac injuries in $\mathrm{db} / \mathrm{db}$ mice Figure 7 indicates that cardiac interstitial fibrosis, pericoronary arterial fibrosis, coronary arterial thickening, cardiac interstitial macrophage infiltration, and cardiac superoxide were significantly greater in $\mathrm{db} / \mathrm{db}$ mice than in $\mathrm{db} / \mathrm{m}$ mice. Ten weeks of empagliflozin treatment significantly ameliorated cardiac interstitial fibrosis $(\mathrm{p}<0.05)$,

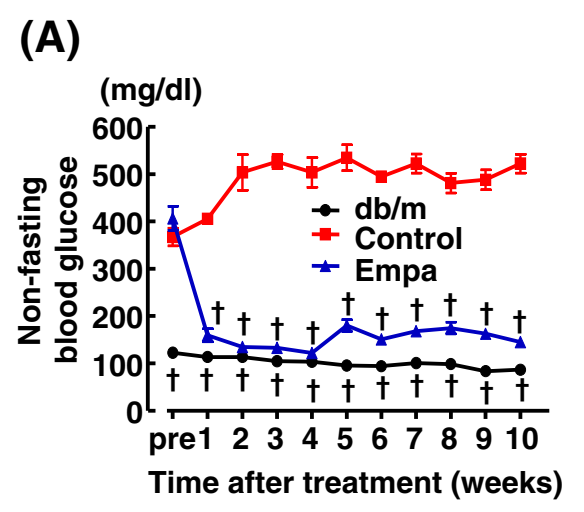

(C)

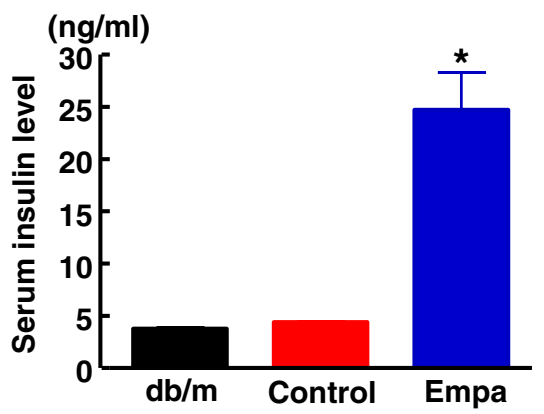

(B)

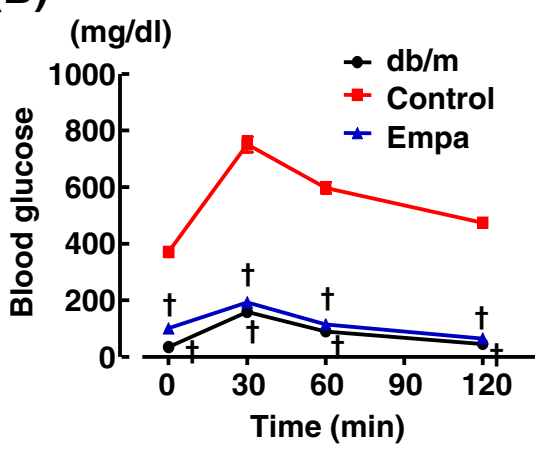

(D)

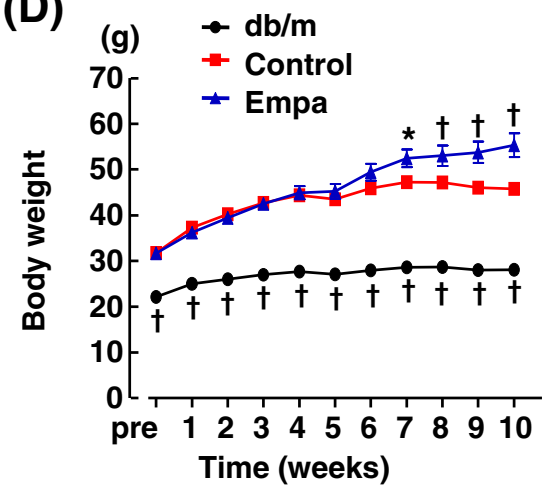

Figure 5 Effects of long-term (10 weeks) empagliflozin administration on non-fasting blood glucose (A), oral glucose tolerance test (B), serum insulin levels (C), and body weight (D) of $\mathbf{d b} / \mathbf{d b}$ mice. Abbreviations: $\mathrm{db} / \mathrm{m}$, non-diabetic $\mathrm{db} / \mathrm{m}$ mice; Control, control (untreated) $\mathrm{db} / \mathrm{db}$ mice; Empa, empagliflozin-treated db/db mice. ${ }^{*} p<0.05,+p<0.01$, vs control db/db mice. Values are mean \pm SEM $(n=9-11)$. 
(A)

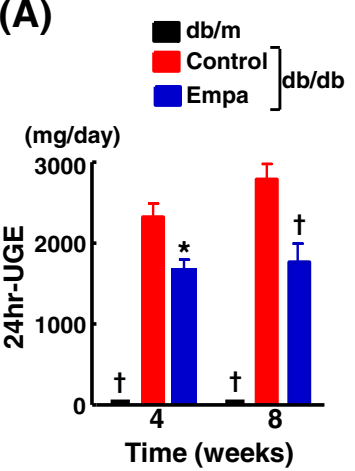

(D)

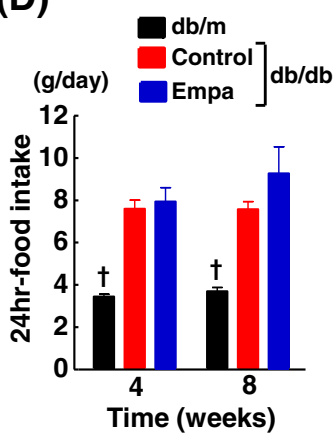

(B)

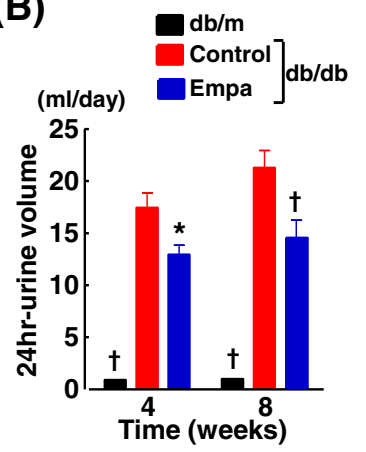

(E)

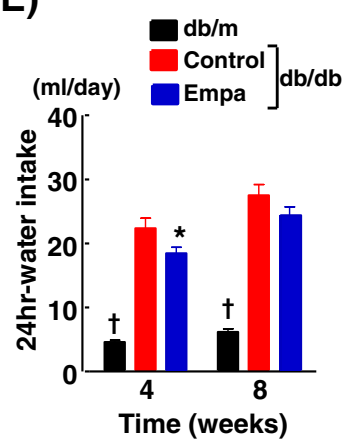

(C)
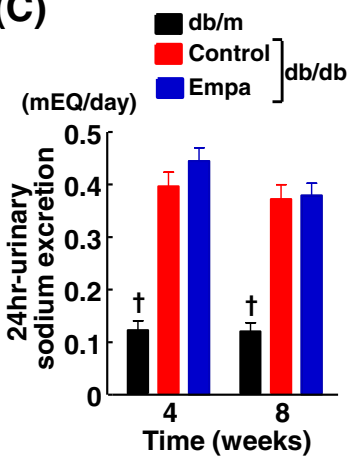

(F)

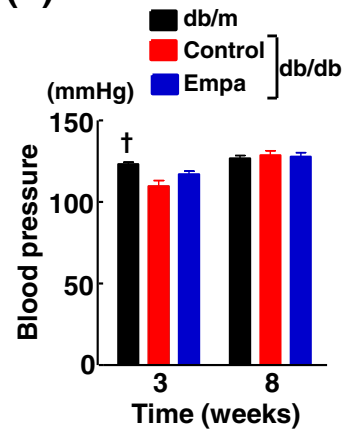

Figure 6 Effects of long-term empagliflozin administration on urinary glucose excretion (UGE) (A), urine volume (B), urinary sodium excretion (C), food intake (D), water intake (E), and blood pressure (F) of db/db mice. Abbreviations used are the same as in Figure 5. ${ }^{*} p<0.05,+p<0.01$ vs control db/db mice. Values are mean \pm SEM $(n=9-11)$.

peri-coronary arterial fibrosis $(\mathrm{p}<0.05)$, coronary arterial thickening $(\mathrm{P}<0.05)$, cardiac interstitial macrophage infiltration $(\mathrm{p}<0.01)$, and cardiac superoxide levels $(\mathrm{p}<0.01)$ in $\mathrm{db} / \mathrm{db}$ mice.

Effects of empagliflozin on vascular dilating function and aortic superoxide in $\mathrm{db} / \mathrm{db}$ mice

As shown in Figure 8(A), vascular endothelium-dependent relaxation by acetylcholine in $\mathrm{db} / \mathrm{db}$ mice was significantly impaired compared with nondiabetic $\mathrm{db} / \mathrm{m}$ mice. Treatment with empagliflozin significantly ameliorated the impairment of vascular endothelial function compared with control $\mathrm{db} / \mathrm{db}$ mice. Vascular endothelium-independent relaxation by $\mathrm{S}-$ nitroso-N-acetylpenicillamine (SNAP) was slightly but significantly impaired in $\mathrm{db} / \mathrm{db}$ mice compared with $\mathrm{db} / \mathrm{m}$ mice, and empagliflozin partially ameliorated the impairment of SNAP-induced vascular relaxation (Figure $8(\mathrm{~B})$ ). As shown in Figure $8(\mathrm{C})$, aortic superoxide levels were significantly greater in $\mathrm{db} / \mathrm{db}$ mice than $\mathrm{db} / \mathrm{m}$ mice $(\mathrm{p}<0.01)$. Empagliflozin significantly reduced aortic superoxide in $\mathrm{db} / \mathrm{db}$ mice $(\mathrm{p}<0.01)$.

Effects of empagliflozin on cognitive function of $\mathrm{db} / \mathrm{db}$ mice As shown by the Morris water maze test in Figure 9, 16 -week-old $\mathrm{db} / \mathrm{db}$ mice showed significantly impaired learning and reference/working memory compared with the age-matched $\mathrm{db} / \mathrm{m}$ mice. Escape latency of the hidden plat form test was greater in control $\mathrm{db} / \mathrm{db}$ mice than in nondiabetic $\mathrm{db} / \mathrm{m}$ mice $(\mathrm{p}<0.01)$, and empagliflozin treatment significantly decreased the increased escape latency in $\mathrm{db} / \mathrm{db}$ mice $(\mathrm{p}<0.01)$ (Figure $9(\mathrm{~A})$ ). Number of times across the platform in the probe test was smaller in control $\mathrm{db} / \mathrm{db}$ mice than in $\mathrm{db} / \mathrm{m}$ mice $(\mathrm{p}<0.01)$, and empagliflozin reversed it in $\mathrm{db} / \mathrm{db}$ mice $(\mathrm{p}<0.01)$ (Figure 9 (B)). There was no difference between empagliflozintreated and control $\mathrm{db} / \mathrm{db}$ mice regarding escape latency in the visible test (Figure $9(\mathrm{C})$ ) or swimming speeds (Figure 9 (D)).

Effects of empagliflozin on cerebral oxidative stress and brain-derived neurotrophic factor of $\mathrm{db} / \mathrm{db}$ mice

Empagliflozin treatment significantly ameliorated cerebral superoxide $(\mathrm{P}<0.01)$ (Figure $10(\mathrm{~A})-(\mathrm{C})$ ) and $8-\mathrm{OHdG}$, a marker of DNA oxidative damage $(\mathrm{P}<0.01)$ (Figure 10 (D)) in $\mathrm{db} / \mathrm{db}$ mice. The attenuation of cerebral oxidative stress by empagliflozin was associated with the reduction of cerebral NADPH oxidase subunits, gp91 $(\mathrm{P}<0.05)$ and p67 $(\mathrm{P}<0.01)$ (Figure $10(\mathrm{E})(\mathrm{F}))$. Moreover, empagliflozin treatment significantly augmented cerebral BDNF levels in $\mathrm{db} / \mathrm{db}$ mice $(\mathrm{P}<0.05)$. 
(A)

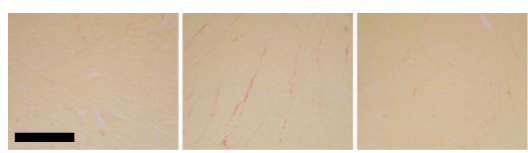

(\%)

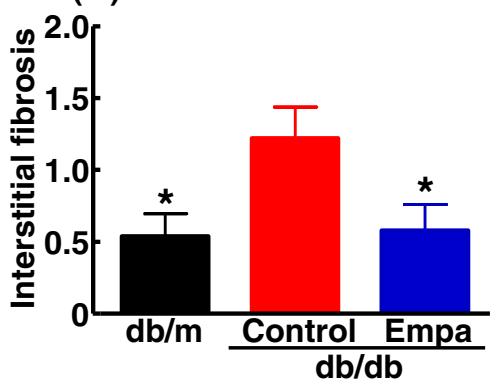

(C)
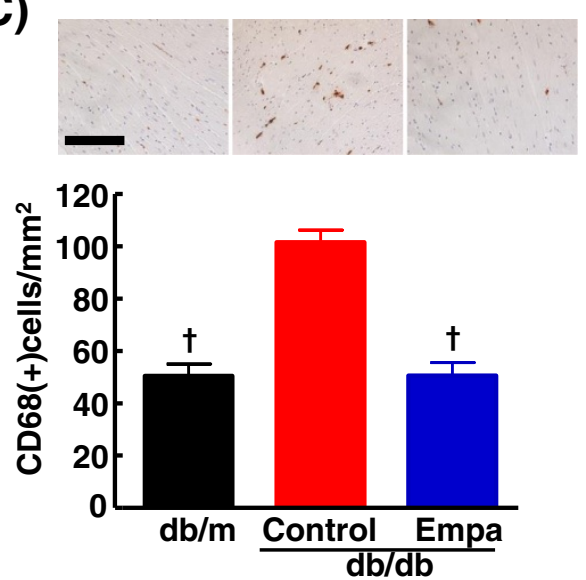

(B)

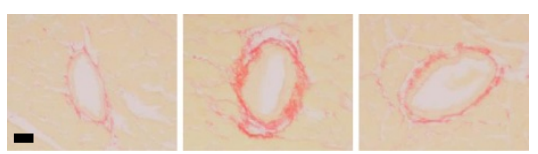

(\%)

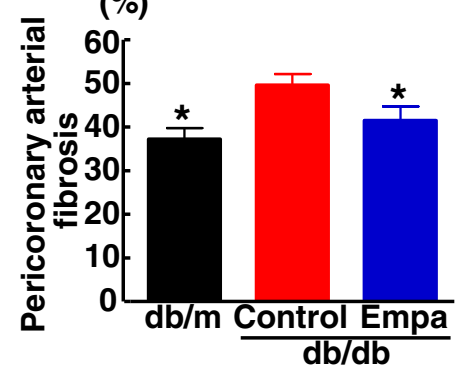

(\%)

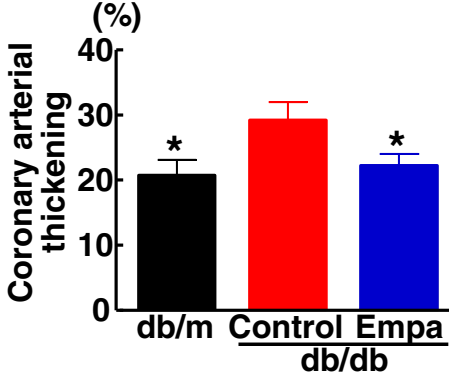

(D)

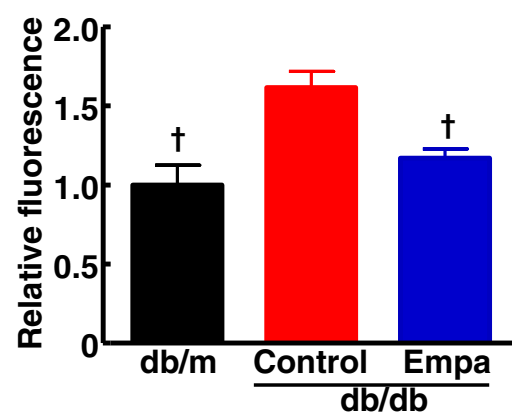

Figure 7 Effect of long-term empagliflozin treatment on cardiac interstitial fibrosis (A), peri-coronary arterial fibrosis and coronary arterial thickening (B), cardiac macrophage infiltration (C) and cardiac superoxide (D) in db/db mice. Upper panels in (A) and (B) indicate representative photomicrographs of cardiac sections stained with Sirius red. Upper panels in (C) and (D) indicate representative photomicrographs of cardiac sections stained with CD68 antibody and dihydroethidium, respectively. Abbreviations used are the same as in Figure $5 .{ }^{*} p<0.05,+p<0.01$ vs control db/db mice. Values are mean \pm SEM ( $n=9-11)$. Bar $=100 \mu \mathrm{m}$ in (A), (C), and (D). Bar $=50 \mu \mathrm{m}$ in (B).

Effects empagliflozin on renal complication of $\mathrm{db} / \mathrm{db}$ mice $\mathrm{db} / \mathrm{db}$ mice exhibited higher ratio of urinary albumin to creatinine excretions, higher glomerular sclerosis index, greater glomerular macrophage infiltration, and larger glomerular superoxide than nondiabetic $\mathrm{db} / \mathrm{m}$ mice (Figure 11). Treatment of $\mathrm{db} / \mathrm{db}$ mice with empagliflozin significantly ameliorated all these parameters related to glomerular injury.

\section{Discussion}

Despite a number of therapeutic options, hyperglycemia in diabetic patients is often poorly controlled. SGLT2 inhibitors represent a novel class of drugs for treatment of type 2 diabetes and exert insulin-independent blood glucose lowering effects through the inhibition of glucose reabsorption and subsequent increase of urinary glucose excretion [12-14]. Furthermore, SGLT2 inhibitors do not increase the risk of hypoglycemia. Thus, SGLT2 inhibitors are expected to be a novel and promising agent for treatment of type 2 diabetes. Empagliflozin is a selective inhibitor of SGLT2 with good safety profile and does not require dose adjustments in patients with renal impairment [31-34]. The major findings of this study was that glycemic control with empagliflozin significantly ameliorated cardiac fibrosis and inflammation, coronary arterial remodeling, vascular dysfunction, and cognitive impairment in obese and type 2 diabetic mice. Furthermore, these beneficial effects of empagliflozin on cardiovascular injury and cognitive impairment were associated with the significant attenuation of oxidative stress in cardiovascular and cerebral tissues. These observations provide the experimental evidence supporting that empagliflozin may be a promising therapeutic agent for macrovascular complications and cognitive decline in type 2 diabetes. 

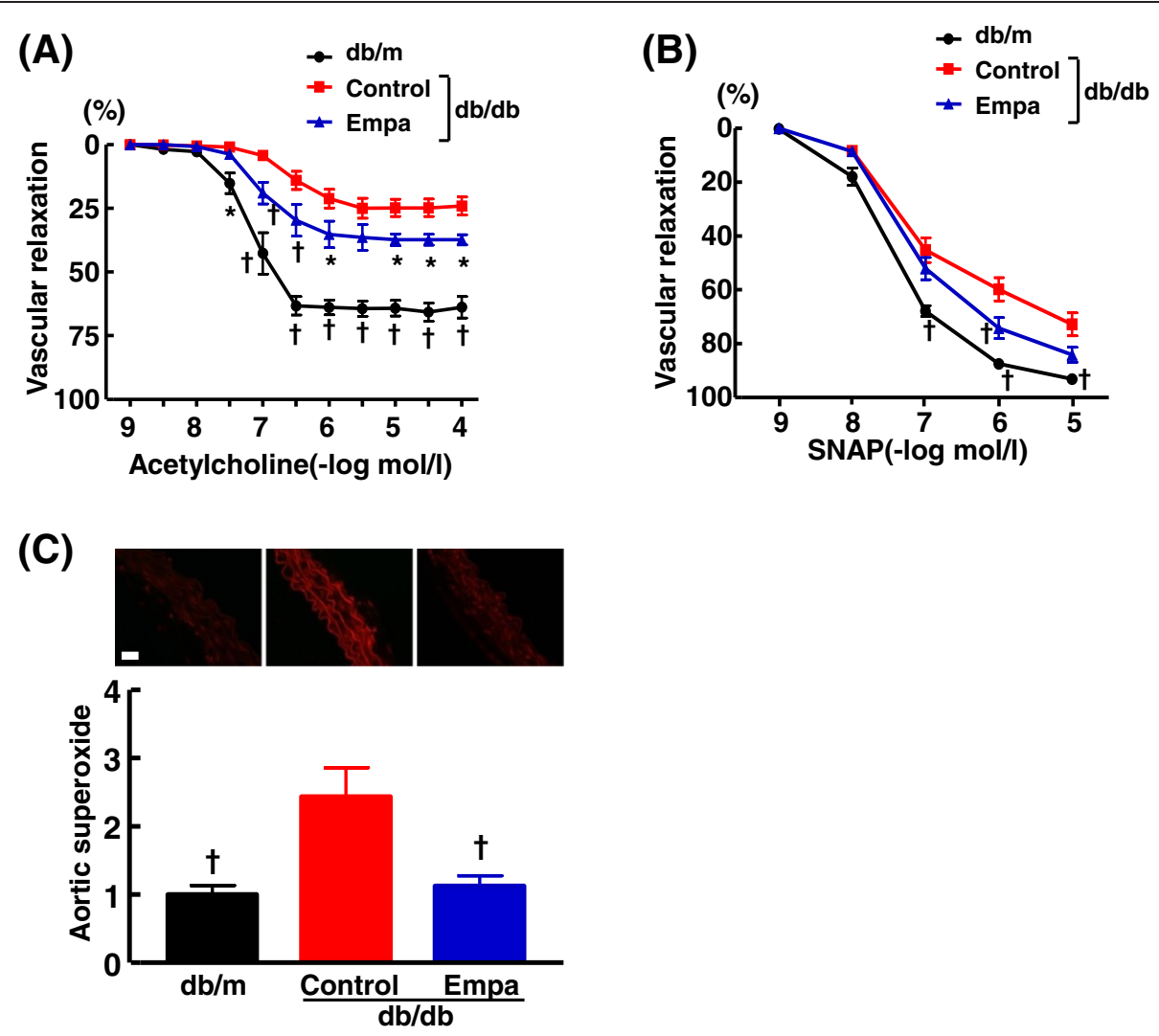

Figure 8 Effect of long-term empagliflozin treatment on vascular relaxation by acetylcholine (A) and by SNAP (B), and vascular superoxide (C) in thoracic aortas of $\mathbf{d b} / \mathbf{d b}$ mice. Upper panels in (C) are representative photomicrographs of dihydroethidium-stained aortic section. Bar $=50 \mu \mathrm{m}$. Abbreviations used are the same as in Figure $5 .{ }^{*} p<0.05,+p<0.01$, vs control db/db mice. Values are mean \pm SEM $(n=9-11)$.

Macrovascular disease is the leading cause of mortality in diabetic patients and the burden of cardiovascular disease due to diabetes mellitus has gone on increasing $[1,2]$. Although strict glycemic control is well established to reduce diabetic microvascular complications such as nephropathy or retinopathy, the benefit of glycemic control in preventing the macrovascular complications have been difficult to establish and there have been conflicting findings from previous large clinical trials [3-5,7]. Furthermore, dipeptidyl-peptidase IV inhibitors, a novel class of antidiabetic agent, have been recently reported to fail to improve cardiovascular outcomes in large clinical trials [6,8,12-14]. A multiple lines of experimental studies $[17,20,21]$ on type 1 or type 2 diabetic animals show that glycemic control with SGLT2 inhibitors reduces the progression of diabetic nephropathy, one of the major microvascular complications attributable to diabetes. However, to our knowledge, it remains to be determined whether the SGLT2 inhibitor can protect against cardiovascular disease or cognitive impairment. Therefore, in the present study, we examined the effect of empagliflozin, a SGLT2 inhibitor, on cardiovascular injury and cognitive function in $\mathrm{db} / \mathrm{db}$ mice, a useful model of obesity and type 2 diabetes.

In the present study, we obtained the evidence that empagliflozin ameliorated cardiac fibrosis and inflammation, coronary arterial remodeling, and the impairment of vascular dilating function in obese type 2 diabetic mice. Accumulating evidence [35-37] establish that hyperglycemia enhances tissue oxidative stress which plays a key role in the pathophysiology of diabetes mellitus and its complications. Therefore, in this study, we examined the effect of empagliflozin on cardiovascular oxidative stress in $\mathrm{db} / \mathrm{db}$ mice, and found that empagliflozin attenuated the oxidative stress in cardiac and vascular tissues of $\mathrm{db} / \mathrm{db}$ mice. We have previously reported that direct attenuation of oxidative stress in $\mathrm{db} / \mathrm{db}$ mice with antioxidant causes the amelioration of cardiovascular injury, thereby demonstrating the direct involvement of oxidative stress in the progression of cardiovascular injury in $\mathrm{db} / \mathrm{db}$ mice [28]. Taken together, our present observations support the notion that the amelioration of cardiovascular injury by empagliflozin might be attributable to the attenuation of tissue oxidative stress. 


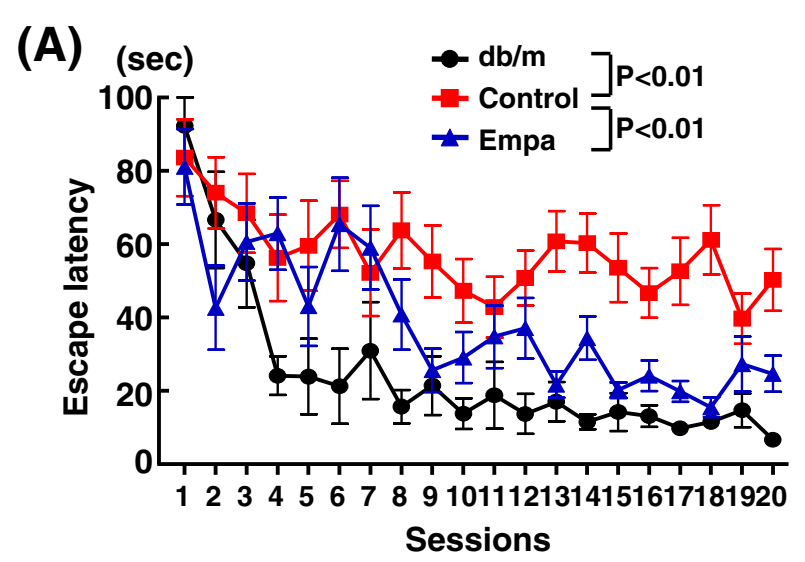

(C)

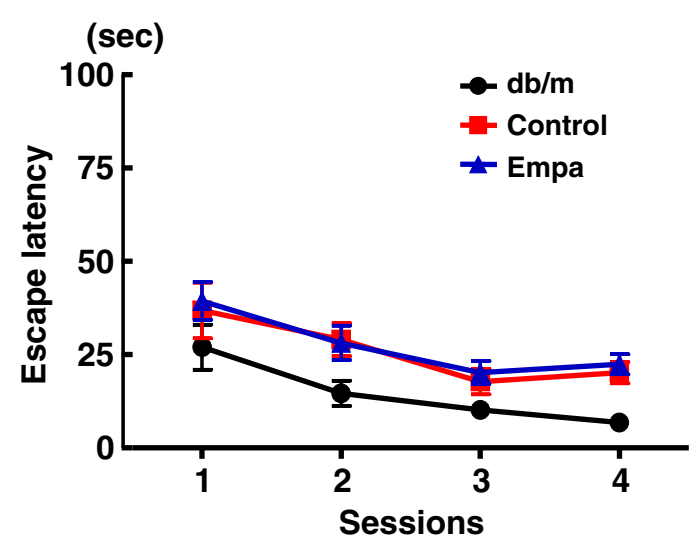

(B)

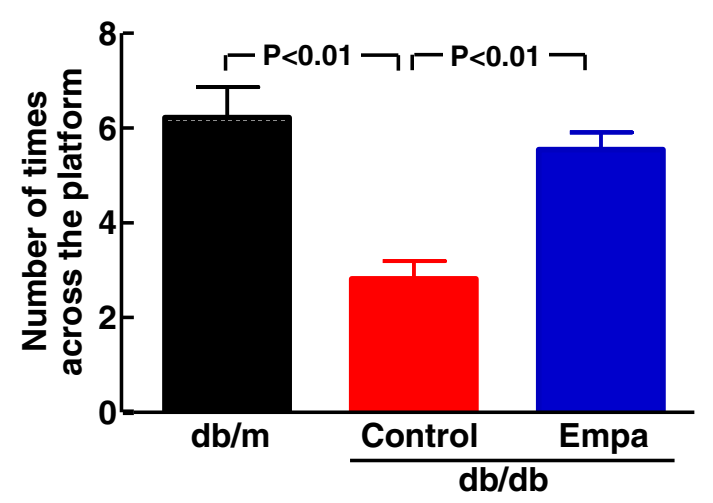

(D)

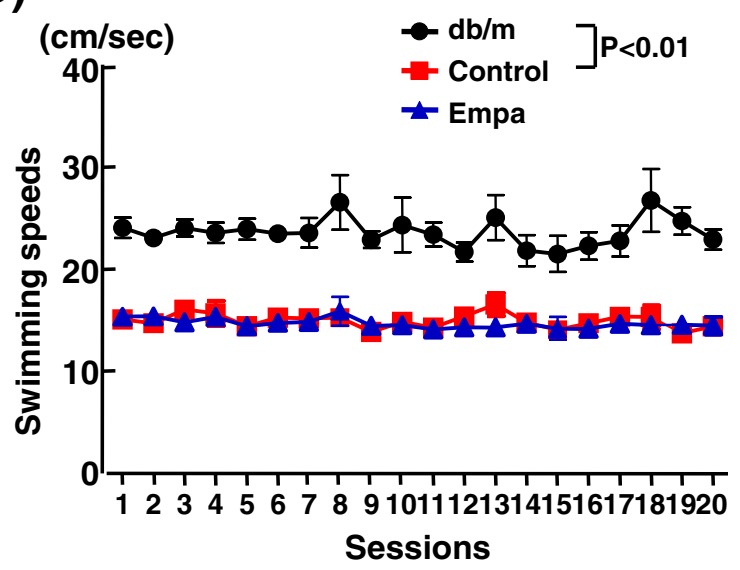

Figure 9 Effect of long-term empagliflozin treatment on cognitive function of $\mathrm{db} / \mathrm{db}$ mice estimated by Morris water maze test. Cognitive function was evaluated by Morris water maze test at 9 weeks after the treatment. (A) indicates escape latency of the hidden platform test on 4 consecutive days (1-20 sessions). (B) indicates number of times across the platform in the probe test. (C) indicates escape latency in the visible test. (D) indicates swimming speeds. Abbreviations used are the same as in Figure 5. Values are mean \pm SEM $(n=9-11)$.

Diabetes is one of the major risk factors responsible for cognitive deficits such as Alzheimer's disease and vascular dementia [9-11]. However, the potential benefit of anti-diabetic agents in prevention of cognitive deficits is unknown. Previous studies [38-40] demonstrate that $\mathrm{db} / \mathrm{db}$ mice are characterized by impaired cognitive performance, thereby being regarded as a useful model to investigate cognitive decline attributable to diabetes. Therefore, in this study, we investigated the effect of empagliflozin on cognitive function in $\mathrm{db} / \mathrm{db}$ mice. Of note, empagliflozin significantly prevented the progression of cognitive impairment (learning and reference/working memory) in diabetic mice, as shown by the findings on water maze test. To examine the potential mechanism underlying the amelioration of cognitive impairment by empagliflozin, we examined the effects of empagliflozin on cerebral oxidative stress. We found that empagliflozin treatment significantly attenuated cerebral oxidative stress and DNA oxidative damage in $\mathrm{db} / \mathrm{db}$ mice, as shown by the reduction of cerebral superoxide and 8-OHdG, and this attenuation of cerebral oxidative stress was associated with the reduction of cerebral NADPH oxidase subunits, gp91phox and p67phox levels. Therefore, the improvement of cognitive function by empagliflozin seems to be attributed to the attenuation of oxidative stress. Moreover, we also examined the effect of empagliflozin treatment on cerebral BDNF, since BDNF [32], a key protein promoting memory and survival of neurons, is significantly reduced in diabetic patients and diabetic animals $[31,41]$ including $\mathrm{db} / \mathrm{db}$ mice [42] and the decrease in cerebral BDNF is shown to be associated with cognitive decline $[41,43]$. Interestingly, empagliflozin treatment significantly increased cerebral BDNF levels in $\mathrm{db} / \mathrm{db}$ mice. These observations provided the evidence supporting that the increase in BDNF as well as the attenuation of oxidative stress appears to be responsible for the mechanism 


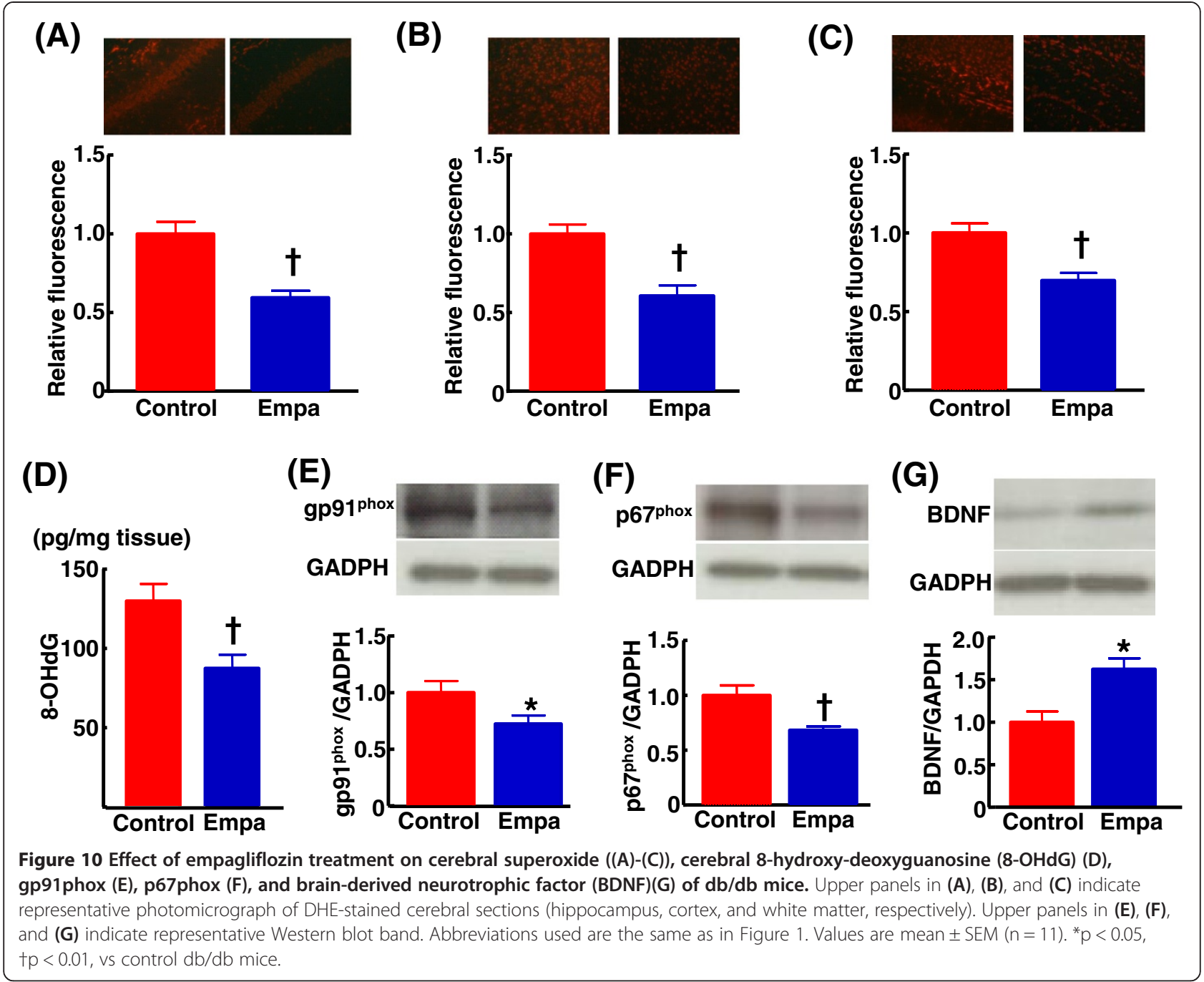

of prevention of cognitive impairment by empagliflozin. Thus, glycemic control with empagliflozin is proposed to be potentially a promising strategy for prevention of diabetes-induced cognitive deficits. However, future clinical study is needed to define our proposal.

In this study, we also examined the effects of empagliflozin on glomerular injury in $\mathrm{db} / \mathrm{db}$ mice. We found that empagliflozin exerts protective effects against diabetic nephropathy, as shown by the reduction of urinary albumin excretion, glomerular sclerosis index, glomerular macrophage infiltration, and glomerular superoxide in $\mathrm{db} / \mathrm{db}$ mice with empagliflozin. Our present results are in good agreement with previous reports regarding various SGLT2 inhibitors [17-19,41,44] including empagliflozin [16]. Thus, our present work confirms previous experimental findings supporting the benefit of SGLT2 inhibitors in prevention of diabetic nephropathy.

High blood pressure as well as diabetes is a major risk factor for cardiovascular disease and cognitive decline.
Interestingly, clinical findings on type 2 diabetic patients demonstrate that SGLT2 inhibitors including empagliflozin significantly reduce blood pressure in diabetic patients $[13,15]$. Therefore, in this study, we also measured blood pressure in $\mathrm{db} / \mathrm{db}$ mice. However, we found no significant alteration of blood pressure in $\mathrm{db} / \mathrm{db}$ mice treated with empagliflozin. Thus, the protective effects of empagliflozin against cardiovascular and glomerular injuries, and cognitive impairment in $\mathrm{db} / \mathrm{db}$ mice seems not to be attributed to blood pressure.

Accumulating clinical data show that SGLT2 inhibitors including empagliflozin reduces body weight in type 2 diabetic patients and glucose lowering action of SGLT2 inhibitors is insulin-independent [12-14,31]. In the longterm experiment of the present study, serum insulin levels were higher and the body weight was greater in empagliflozin-treated $\mathrm{db} / \mathrm{db}$ mice than in control (untreated) $\mathrm{db} / \mathrm{db}$ mice. However, it is unlikely that the higher insulin levels and greater body weight in 


\section{(A)}

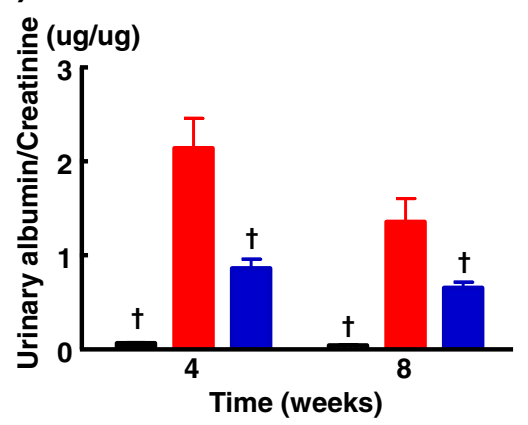

(C)

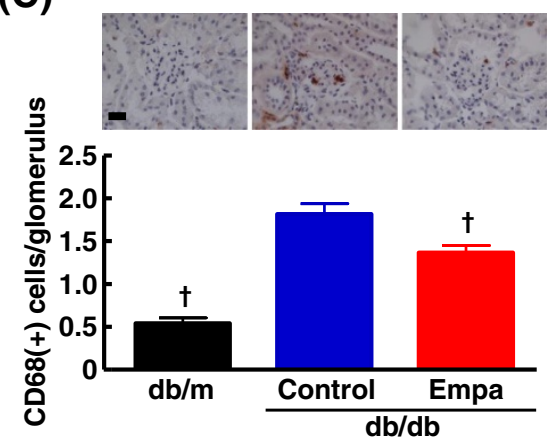

(B)

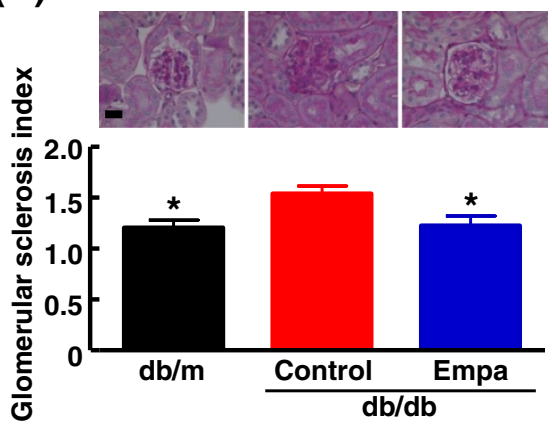

(D)

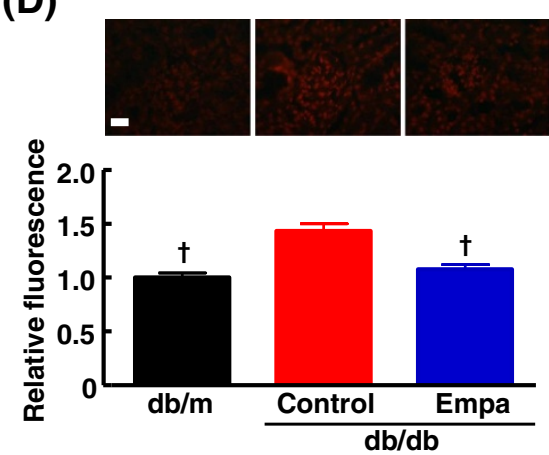

Figure 11 Effects of empagliflozin on urinary albumin/creatinine ratio (A), glomerular sclerosis (B), glomerular macrophage infiltration (C) and glomerular superoxide (D) of $\mathbf{d b} / \mathbf{d b}$ mice. Urinary albumin/creatinine ratio in (A) was measured at 4 and 8 weeks after start of drug treatment. Upper panels in (B), (C), and (D) indicate representative photomicrographs of renal sections stained with PAS, CD68 antibody, and dihydroethidium, respectively. Abbreviations used are the same as in Figure 5. ${ }^{*} p<0.05,+p<0.01$ vs control db/db mice. Values are mean \pm SEM $(n=9-11) . B a r=50 \mu m$ in (B), (C), and (D).

empagliflozin-treated $\mathrm{db} / \mathrm{db}$ mice is mediated by the direct action of empagliflozin. Along with aging, $\mathrm{db} / \mathrm{db}$ mice are shown to exhibit the exhaustion of pancreatic $\beta$-cells because of long-standing glucose toxicity attributed to severe hyperglycemia and subsequently exhibit progressive decrease in serum insulin levels and loss of body weight gain $[26,28,44]$. Taken together with the findings that empagliflozin treatment substantially improved hyperglycemia, the greater body weight and the higher serum insulin levels in empagliflozin-treated $\mathrm{db} / \mathrm{db}$ mice than in control (untreated) $\mathrm{db} / \mathrm{db}$ mice can be explained by the significant prevention by empagliflozin of aging-associated decrease in serum insulin levels and of aging-associated loss of body weight gain in $\mathrm{db} / \mathrm{db}$ mice.

The data on short-term (7 days) empagliflozin administration in $\mathrm{db} / \mathrm{db}$ mice indicates that the significant increase in 24-hour urinary glucose excretion on day 1 after start of empagliflozin treatment was accompanied by not only the remarkable reduction of blood glucose but also the significant and transient increase in urine volume and urinary sodium excretion, and the significant decrease in body weight gain. However, from day 2 after the treatment, despite the remarkable continuous reduction of blood glucose, empagliflozin did not increase urinary glucose excretion, urine volume, and urinary sodium excretion in $\mathrm{db} / \mathrm{db}$ mice, compared with control (untreated $\mathrm{db} / \mathrm{db}$ mice). Furthermore, in the experiment on long-term empagliflozin treatment, urinary glucose excretion and urine volume were lower in empagliflozin group than in control group, although empagliflozin group had continuously much less blood glucose levels compared with control group. These paradoxical findings are in good agreement with previous report [44], and can be explained by the fact that the significant reduction of blood glucose levels attributed to the increased urinary glucose excretion with empagliflozin results in the significant decrease in the glucose content in glomerular filtrate and subsequently leads to the decrease in urinary glucose excretion.

\section{Conclusions}

In conclusion, glycemic control with empagliflozin ameliorated cardiac fibrosis and inflammation, coronary arterial remodeling, vascular dysfunction, cognitive decline as well as glomerular injury in obese type 2 diabetic mice, thereby highlighting empagliflozin, a SGLT2 inhibitor, as potentially a promising agent for prevention of diabetic 
macrovascular disease and cognitive decline as well as nephropathy. However, no sufficiently powered clinical trial has yet elucidated the benefit of a SGLT2 inhibitor in prevention of diabetic macrovascular and microvascular complications, although large clinical trials to address this issue are now on going [45].

\section{Abbreviations}

SGLT2: Sodium glucose co-transporter 2; UGE: Urinary glucose excretion; BP: Blood pressure; MWM: Morris water maze test; BDNF: Brain-derived neurotrophic factor; SNAP: S-nitroso-N-acetylpenicillamine; DHE: Dihydroethidium; PAS: Periodic acid-Schiff.

\section{Competing interests}

S. K-M received lecture fees and research grant from Astellas, AstraZeneca, Boehringer Ingelheim, Daiichi Sankyo, Novartis, Sionogi, Takeda, Kyowa Hakko Kirin.

\section{Authors' contributions}

Participated in research design: BL, NK, YH, and SK-M; conducted experiments: $\mathrm{BL}, \mathrm{NK}, \mathrm{YH}, \mathrm{DS}, \mathrm{KT}, \mathrm{KU}, \mathrm{MM}, \mathrm{TN}$, and HK; all authors performed data analysis and interpretation; $\mathrm{BL}, \mathrm{YH}$, and SK-M contributed to the writing of the manuscript and critically revised the manuscript: all authors read and approved the final manuscript.

\section{Acknowledgement}

This work was partially supported by a grant from Boehringer Ingelheim, and was supported by Otsuka Toshimi scholarship foundation.

Received: 25 July 2014 Accepted: 20 October 2014

Published online: 26 October 2014

\section{References}

1. Emerging Risk Factors C, Sarwar N, Gao P, Seshasai SR, Gobin R, Kaptoge S, Di Angelantonio E, Ingelsson E, Lawlor DA, Selvin E, Stampfer M, Stehouwer CD, Lewington S, Pennells L, Thompson A, Sattar N, White IR, Ray KK, Danesh J: Diabetes mellitus, fasting blood glucose concentration, and risk of vascular disease: a collaborative meta-analysis of 102 prospective studies. Lancet 2010, 375:2215-2222.

2. Fox CS, Coady S, Sorlie PD, D'Agostino RB Sr, Pencina MJ, Vasan RS, Meigs JB, Levy D, Savage PJ: Increasing cardiovascular disease burden due to diabetes mellitus: the Framingham Heart Study. Circulation 2007, 115:1544-1550.

3. Action to Control Cardiovascular Risk in Diabetes Study G, Gerstein HC, Miller ME, Byington RP, Goff DC Jr, Bigger JT, Buse JB, Cushman WC, Genuth S, Ismail-Beigi F, Grimm RH Jr, Probstfield JL, Simons-Morton DG, Friedewald WT: Effects of intensive glucose lowering in type 2 diabetes. $N$ Engl J Med 2008, 358:2545-2559.

4. Holman RR, Paul SK, Bethel MA, Matthews DR, Neil HA: 10-year follow-up of intensive glucose control in type 2 diabetes. N Engl J Med 2008, 359:1577-1589.

5. Stratton IM, Adler Al, Neil HA, Matthews DR, Manley SE, Cull CA, Hadden D, Turner RC, Holman RR: Association of glycaemia with macrovascular and microvascular complications of type 2 diabetes (UKPDS 35): prospective observational study. BMJ 2000, 321:405-412.

6. Scirica BM, Bhatt DL, Braunwald E, Steg PG, Davidson J, Hirshberg B, Ohman P, Frederich R, Wiviott SD, Hoffman EB, Cavender MA, Udell JA, Desai NR, Mosenzon O, McGuire DK, Ray KK, Leiter LA, Raz I, Committee S-TS, Investigators: Saxagliptin and cardiovascular outcomes in patients with type 2 diabetes mellitus. N Engl J Med 2013, 369:1317-1326.

7. Singh A, Donnino R, Weintraub H, Schwartzbard A: Effect of strict glycemic control in patients with diabetes mellitus on frequency of macrovascular events. Am J Cardiol 2013, 112:1033-1038.

8. White WB, Cannon CP, Heller SR, Nissen SE, Bergenstal RM, Bakris GL, Perez AT, Fleck PR, Mehta CR, Kupfer S, Wilson C, Cushman WC, Zannad F, Investigators E: Alogliptin after acute coronary syndrome in patients with type 2 diabetes. N Engl J Med 2013, 369:1327-1335.

9. Biessels GJ, Strachan MW, Visseren FL, Kappelle LJ, Whitmer RA: Dementia and cognitive decline in type 2 diabetes and prediabetic stages: towards targeted interventions. Lancet Diabetes Endocrinol 2014, 2:246-255.
10. Matsuzaki T, Sasaki K, Tanizaki Y, Hata J, Fujimi K, Matsui Y, Sekita A, Suzuki SO, Kanba S, Kiyohara Y, Iwaki T: Insulin resistance is associated with the pathology of Alzheimer disease: the Hisayama study. Neurology 2010, 75:764-770.

11. Schrijvers EM, Witteman JC, Sijbrands EJ, Hofman A, Koudstaal PJ, Breteler MM: Insulin metabolism and the risk of Alzheimer disease: the Rotterdam Study. Neurology 2010, 75:1982-1987.

12. Ferrannini $E$, Solini A: SGLT2 inhibition in diabetes mellitus: rationale and clinical prospects. Nat Rev Endocrinol 2012, 8:495-502.

13. Hasan FM, Alsahli M, Gerich JE: SGLT2 inhibitors in the treatment of type 2 diabetes. Diabetes Res Clin Pract 2014, 104:297-322.

14. Monami M, Nardini C, Mannucci E: Efficacy and safety of sodium glucose co-transport-2 inhibitors in type 2 diabetes: a meta-analysis of randomized clinical trials. Diabetes Obes Metab 2014, 16:457-466.

15. Oliva RV, Bakris GL: Blood pressure effects of sodium-glucose co-transport 2 (SGLT2) inhibitors. J Am Soc Hypertens 2014, 8:330-339.

16. Gembardt F, Bartaun C, Jarzebska N, Mayoux E, Todorov VT, Hohenstein B, Hugo C: The SGLT2 inhibitor empagliflozin ameliorates early features of diabetic nephropathy in BTBR ob/ob type 2 diabetic mice with and without hypertension. Am J Physiol Renal Physiol 2014, 307:F317-F325.

17. Kojima N, Williams JM, Takahashi T, Miyata N, Roman RJ: Effects of a new SGLT2 inhibitor, luseogliflozin, on diabetic nephropathy in T2DN rats. J Pharmacol Exp Ther 2013, 345:464-472.

18. Nagata T, Fukuzawa T, Takeda M, Fukazawa M, Mori T, Nihei T, Honda K, Suzuki Y, Kawabe Y: Tofogliflozin, a novel sodium-glucose co-transporter 2 inhibitor, improves renal and pancreatic function in $\mathrm{db} / \mathrm{db}$ mice. Br J Pharmacol 2013, 170:519-531.

19. Terami N, Ogawa D, Tachibana H, Hatanaka T, Wada J, Nakatsuka A, Eguchi J, Horiguchi CS, Nishii N, Yamada H, Takei K, Makino H: Long-term treatment with the sodium glucose cotransporter 2 inhibitor, dapagliflozin, ameliorates glucose homeostasis and diabetic nephropathy in db/db mice. PLoS One 2014, 9:e100777.

20. Thomson SC, Rieg T, Miracle C, Mansoury H, Whaley J, Vallon V, Singh P: Acute and chronic effects of SGLT2 blockade on glomerular and tubular function in the early diabetic rat. Am J Physiol Regul Integr Comp Physiol 2012, 302:R75-R83.

21. Vallon V, Gerasimova M, Rose MA, Masuda T, Satriano J, Mayoux E, Koepsell $H$, Thomson SC, Rieg T: SGLT2 inhibitor empagliflozin reduces renal growth and albuminuria in proportion to hyperglycemia and prevents glomerular hyperfiltration in diabetic Akita mice. Am J Physiol Renal Physiol 2014, 306:F194-F204.

22. Barnett AH, Mithal A, Manassie J, Jones R, Rattunde H, Woerle HJ, Broedl UC, investigators E-RRt: Efficacy and safety of empagliflozin added to existing antidiabetes treatment in patients with type 2 diabetes and chronic kidney disease: a randomised, double-blind, placebo-controlled trial. Lancet Diabetes Endocrinol 2014, 2:369-384.

23. Grempler R, Thomas L, Eckhardt M, Himmelsbach F, Sauer A, Sharp DE, Bakker RA, Mark M, Klein T, Eickelmann P: Empagliflozin, a novel selective sodium glucose cotransporter-2 (SGLT-2) inhibitor: characterisation and comparison with other SGLT-2 inhibitors. Diabetes Obes Metab 2012, 14:83-90.

24. Liakos A, Karagiannis T, Athanasiadou E, Sarigianni M, Mainou M, Papatheodorou K, Bekiari E, Tsapas A: Efficacy and safety of empagliflozin for type 2 diabetes: a systematic review and meta-analysis. Diabetes Obes Metab 2014, 16:984-993.

25. Uekawa K, Hasegawa Y, Ma M, Nakagawa T, Katayama T, Sueta D, Toyama K, Kataoka K, Koibuchi N, Kawano T, Kuratsu J, Kim-Mitsuyama S: Rosuvastatin ameliorates early brain injury after subarachnoid hemorrhage via suppression of superoxide formation and nuclear factor-kappa B activation in rats. J Stroke Cerebrovasc Dis 2014, 23:1429-1439.

26. Dong YF, Liu L, Kataoka K, Nakamura T, Fukuda M, Tokutomi Y, Nako H, Ogawa $\mathrm{H}$, Kim-Mitsuyama S: Aliskiren prevents cardiovascular complications and pancreatic injury in a mouse model of obesity and type 2 diabetes. Diabetologia 2010, 53:180-191.

27. Yamamoto E, Lai ZF, Yamashita T, Tanaka T, Kataoka K, Tokutomi Y, Ito T, Ogawa H, Kim-Mitsuyama S: Enhancement of cardiac oxidative stress by tachycardia and its critical role in cardiac hypertrophy and fibrosis. J Hypertens 2006, 24:2057-2069.

28. Fukuda M, Nakamura T, Kataoka K, Nako H, Tokutomi Y, Dong YF, Ogawa H, Kim-Mitsuyama S: Potentiation by candesartan of protective effects of pioglitazone against type 2 diabetic cardiovascular and renal complications in obese mice. J Hypertens 2010, 28:340-352. 
29. Toyama K, Koibuchi N, Uekawa K, Hasegawa Y, Kataoka K, Katayama T, Sueta D, Ma MJ, Nakagawa T, Yasuda O, Tomimoto H, Ichijo H, Ogawa H, Kim-Mitsuyama $\mathrm{S}$ : Apoptosis signal-regulating kinase 1 is a novel target molecule for cognitive impairment induced by chronic cerebral hypoperfusion. Arterioscler Thromb Vasc Biol 2014, 34:616-625.

30. Dong YF, Kataoka K, Toyama K, Sueta D, Koibuchi N, Yamamoto E, Yata K, Tomimoto H, Ogawa H, Kim-Mitsuyama S: Attenuation of brain damage and cognitive impairment by direct renin inhibition in mice with chronic cerebral hypoperfusion. Hypertension 2011, 58:635-642.

31. Neumiller JJ: Empagliflozin: a new sodium-glucose co-transporter 2 (SGLT2) inhibitor for the treatment of type 2 diabetes. Drugs Context 2014, 3:212262.

32. Ridderstrale M, Svaerd R, Zeller C, Kim G, Woerle HJ, Broedl UC, investigators E-RHHSt: Rationale, design and baseline characteristics of a 4-year (208-week) phase III trial of empagliflozin, an SGLT2 inhibitor, versus glimepiride as add-on to metformin in patients with type 2 diabetes mellitus with insufficient glycemic control. Cardiovasc Diabetol 2013, 12:129.

33. Ring A, Brand T, Macha S, Breithaupt-Groegler K, Simons G, Walter B, Woerle $\mathrm{HJ}$, Broedl UC: The sodium glucose cotransporter 2 inhibitor empagliflozin does not prolong QT interval in a thorough QT (TQT) study. CardiovasC Diabetol 2013, 12:70.

34. Thomas L, Grempler R, Eckhardt M, Himmelsbach F, Sauer A, Klein T, Eickelmann P, Mark M: Long-term treatment with empagliflozin, a novel, potent and selective SGLT-2 inhibitor, improves glycaemic control and features of metabolic syndrome in diabetic rats. Diabetes Obes Metab 2012, 14:94-96.

35. DeRubertis FR, Craven PA, Melhem MF, Salah EM: Attenuation of renal injury in $\mathrm{db} / \mathrm{db}$ mice overexpressing superoxide dismutase: evidence for reduced superoxide-nitric oxide interaction. Diabetes 2004, 53:762-768.

36. Kaneto H, Kajimoto Y, Miyagawa J, Matsuoka T, Fujitani Y, Umayahara Y, Hanafusa T, Matsuzawa Y, Yamasaki Y, Hori M: Beneficial effects of antioxidants in diabetes: possible protection of pancreatic beta-cells against glucose toxicity. Diabetes 1999, 48:2398-2406.

37. Takimoto E, Kass DA: Role of oxidative stress in cardiac hypertrophy and remodeling. Hypertension 2007, 49:241-248.

38. Stranahan AM, Arumugam TV, Cutler RG, Lee K, Egan JM, Mattson MP: Diabetes impairs hippocampal function through glucocorticoid-mediated effects on new and mature neurons. Nat Neurosci 2008, 11:309-317.

39. Ramos-Rodriguez JJ, Ortiz O, Jimenez-Palomares M, Kay KR, Berrocoso E, Murillo-Carretero Ml, Perdomo G, Spires-Jones T, Cozar-Castellano I, Lechuga-Sancho AM, Garcia-Alloza M: Differential central pathology and cognitive impairment in pre-diabetic and diabetic mice. Psychoneuroendocrinology 2013, 38:2462-2475.

40. Li XL, Aou S, Oomura Y, Hori N, Fukunaga K, Hori T: Impairment of long-term potentiation and spatial memory in leptin receptor-deficient rodents. Neuroscience 2002, 113:607-615.

41. Osorio H, Coronel I, Arellano A, Pacheco U, Bautista R, Franco M, Escalante B: Sodium-glucose cotransporter inhibition prevents oxidative stress in the kidney of diabetic rats. Oxid Med Cell Longev 2012, $2012: 542042$.

42. Dinel AL, Andre C, Aubert A, Ferreira G, Laye S, Castanon N: Cognitive and emotional alterations are related to hippocampal inflammation in a mouse model of metabolic syndrome. PLoS One 2011, 6:e24325.

43. Navaratna D, Guo SZ, Hayakawa K, Wang X, Gerhardinger C, Lo EH: Decreased cerebrovascular brain-derived neurotrophic factor-mediated neuroprotection in the diabetic brain. Diabetes 2011, 60:1789-1796.

44. Arakawa K, Ishihara T, Oku A, Nawano M, Ueta K, Kitamura K, Matsumoto M, Saito A: Improved diabetic syndrome in C57BL/KsJ-db/db mice by oral administration of the $\mathrm{Na}(+)$-glucose cotransporter inhibitor T-1095. Br J Pharmacol 2001, 132:578-586

45. Foote C, Perkovic V, Neal B: Effects of SGLT2 inhibitors on cardiovascular outcomes. Diab Vasc Dis Res 2012, 9:117-123.

doi:10.1186/s12933-014-0148-

Cite this article as: Lin et al: Glycemic control with empagliflozin, a novel selective SGLT2 inhibitor, ameliorates cardiovascular injury and cognitive dysfunction in obese and type 2 diabetic mice. Cardiovascular Diabetology 2014 13:148.

\section{Submit your next manuscript to BioMed Central and take full advantage of:}

- Convenient online submission

- Thorough peer review

- No space constraints or color figure charges

- Immediate publication on acceptance

- Inclusion in PubMed, CAS, Scopus and Google Scholar

- Research which is freely available for redistribution 